\title{
Vector manipulation by a semi-persistent plant virus through disease symptom expression
}

Diego F. Vasquez ${ }^{1,2}$, Felipe Borrero-Echeverry ${ }^{2 *}$, Diego F. Rincon ${ }^{2}$

${ }^{1}$ Universidad Nacional de Colombia- Sede Bogotá. Cra 45 \#2685, Bogotá

${ }^{2}$ Corporación Colombiana de Investigación Agropecuaria - AGROSAVIA. Centro de

Investigación Tibaitatá, Km 14 vía Mosquera-Bogotá, Mosquera, Colombia

* Corresponding Author

Email addresses: dfvasquezm@unal.edu.co (DFV), drincon@agrosavia.co (DFR), fborrero@agrosavia.co (FB-E) 


\section{Abstract}

2 The greenhouse whitefly (GWF), Trialeurodes vaporariorum (Westwood) (Hemiptera:

3 Aleyrodidae) is rarely associated with potato plants yet is the only known vector of the

$4 \quad$ Potato yellow vein virus (PYVV). A host shift related with vector’s cognition often requires

5 neural alterations by the virus. However, PYVV, being semi-persistent, is not supposed to

6 directly affect vector physiology. As such, we propose that changes in potato plants caused

7 by PYVV infection should manipulate insect behaviour to increase transmission. Here, we

8 studied the effect of PYVV infection and symptom expression on GWF biological

9 parameters, and attraction towards infected and uninfected potato plants. We compared

10 survival and development rates of GWF nymphs fed with PYVV-infected plants

11 (symptomatic and asymptomatic) and healthy plants under controlled conditions. We also

12 carried out free-choice tests to determine host preference of GWF adults as a function of

13 PYVV infection and disease symptom expression. We found that PYVV infection (both

14 symptomatic and asymptomatic) reduce GWF survival while increasing development time

15 (in symptomatic plants). Combined, a prolonged development time and reduced survival

16 should favour viral uptake and trigger migration of vectors from symptomatic plants short

17 after acquiring the virus. We also found that symptom expression (yellowing) causes

18 significantly greater GWF attraction and establishment compared to healthy or

19 asymptomatic plants. Interestingly, we found that GWF adults that have previously fed on

20 infected plants switch their host preference choosing and establishing on healthy potato

21 plants, which clearly increases horizontal transmission rates. The mechanism through

22 which this behavioural manipulation takes place is not yet well understood. Our results

23 show that symptoms associated with PYVV infection may account for a set of behavioural 
24 modifications that make an improbable vector, such as the GWF, into an efficient agent that

25 increases horizontal transmission rates of PYVV.

26 Highlights

- PYVD reduces the survival of GWF and increases development time when symptoms occur

- PYVD symptom makes potato, a non-host plant, attractive to GWF

- $\quad$ After feeding on infected plants, GWF preference changes to prefer uninfected plants

- PYVV modulates GWF behaviour to enhance horizontal transmission between plants

\section{Introduction}

37 Viruses rely on hosts for replication, which is always detrimental to the host. As obligate

38 parasites, viruses need to move from one host to another to persist which means that they

39 require efficient mechanisms to enhance transmission rates. Plant viruses face additional

40 difficulties since their hosts are immobile, which reduces the probability of transmission

41 through direct contact between infected and uninfected individuals which is why many

42 plant viruses rely on arthropod vectors (Hamelin, Allen, Prendeville, Hajimorad, \& Jeger,

43 2016; Jia et al., 2018). Vector transmission rates are often positively correlated with within-

44 host multiplication rates and virulence (Pagán, Montes, Milgroom, \& García-Arenal, 2014),

45 but virulence may also increase host mortality, reducing the infectious period and 
46 transmission rates. In fact, a wide body of evidence supports the trade-off hypothesis,

47 which states that the level of virulence is driven by the optimum balance between within-

48 and among-host parasite fitness traits (Alizon, Hurford, Mideo, \& Van Baalen, 2009).

49 Some vector-borne plant viruses can be transmitted both horizontally and vertically. In such

50 cases, the level of virulence is often negatively correlated with host's fitness and, thus,

51 expected to vary as a function of the transmission mode: virulence of virus strains selected

52 for horizontal transmission is expected to be higher than that caused by their counterparts

53 adapted for vertical transmission (Lipsitch, Siller, \& Nowak, 1996). In the short-term,

54 however, virulence and transmission mode may depend greatly on internal virus-host

55 interactions, which will allow (or impede) viral particles to either multiply repeatedly at a

56 cost to host fitness or reach its reproductive structures relatively harmlessly. Transmission

57 mode is expected to be subjected to disruptive selection, i.e., both extremes vertical and

58 horizontal are benefited against intermediate strains (Messenger, Molineux, \& Bull, 1999),

59 which implies that one transmission mode should be triggered according to the level of

60 virulence achieved. While vertical transmission relies mainly on host survival and

61 reproduction, horizontal transmission depends on vector attraction, arrestment and posterior

62 migration to a healthy plant, all of which are, in part, mediated by biotic and abiotic

63 conditions (plant nutrition and defences, climatic conditions, host availability) (Gallet,

64 Michalakis, \& Blanc, 2018; Kerry E. Mauck, Chesnais, \& Shapiro, 2018; Su et al., 2015).

65 Furthermore, the high level of virulence associated with vector-mediated transmission (i.e.,

66 horizontal) should activate mechanisms that increase the probability of vectors carrying

67 viral particles from infected to healthy hosts. 
68 Symptom expression in host plants is usually associated with high levels of virulence and

69 horizontal transmission of vector-borne viruses (Bosque-Pérez \& Eigenbrode, 2011;

70 Casteel \& Jander, 2013; Kerry E Mauck, De Moraes, \& Mescher, 2016). Viruses often

71 manipulate vector behaviour to increase movement between infected and healthy hosts, but

72 the behaviours which need to be manipulated depends on the modality of transmission,

73 which may be persistent, non-persistent, or semi-persistent (Ng \& Zhou, 2015). Even

74 though all three benefit by manipulating symptoms to increase vector attraction towards

75 infected plants, they differ in their need to retain the insect vector. Persistent viruses

76 require greater arrestment since insects need to feed for longer periods of time for the virus

77 to reach the gut and allow viral replication inside the vector. Conversely, the non-persistent

78 viruses require low arrestment times since these viruses only persist for a limited time

79 attached to the vector's mouthparts and need to infect new hosts quickly. Semi-persistent

80 viruses, even though they do not replicate in the vector, may persist for a longer time in the

81 vector's salivary glands and as such, require specific arrestment times (enough to be

82 acquired, but not degraded). Disease progression may alter many plant processes and traits

83 to achieve these behavioural changes in insect vectors, including changes in coloration,

84 volatile profiles, alter plant defences, and nutritional quality depending on their mode of

85 transmission (Fereres \& Moreno, 2009; Hogenhout, Ammar, Whitfield, \& Redinbaugh,

86 2008).

87 The Potato yellow vein virus (PYVV), is the causal agent of potato yellow vein disease

88 (PYVD), a re-emerging epidemic of potato crops in northern South America which reduces

89 yields by up to 50\% (Cuadros et al., 2017; Rincon, Vasquez, Rivera-Trujillo, Beltrán, \&

90 Borrero-Echeverry, 2019). PYVV infection is transmitted vertically through infected seed 
91 tubers and horizontally in a semi-persistent manner by the greenhouse whitefly (GWF)

92 Trialeurodes vaporariorum (Westwood) (Hemiptera: Aleyrodidae) (Salazar 2000; Chávez

93 2009). In South America, potato is normally cultivated above 1500 m.a.s.l. which is not

94 optimal for GWF survival and development (Curry \& Pimentel, 1971). Similarly, potato is

95 not a preferred host for GWF under normal conditions, but outbreaks have been observed in

96 association with PYVD (Cuadros et al., 2017). Furthermore, symptom expression of PYVD

97 is associated with reduction in number and weight of tubers produced, while infected,

98 asymptomatic plants vertically transmit the virus without showing such a yield reduction

99 (Guzmán-Barney, Franco-Lara, Rodríguez, Vargas, \& Fierro, 2012). Combined, these facts

100 would suggest that GWF should be a poor vector for PYVV and that in order for it to be

101 attracted towards infected potato plants, symptoms associated with PYVV virulence should

102 be strong modulators of GWF behaviour.

103 We hypothesize that symptom expression of PYVD increases the attraction of GWF

104 towards infected potato plants, but that arrestment should be low in symptomatic plants.

105 Here, we studied the effect of symptom expression on population parameters and

106 behavioural manipulation of GWF. We show that symptom expression has a negative effect

107 on GWF development and survival. We also show that symptom expression differentially

108 modulates GWF behaviour, depending on whether the vector has fed on healthy or infected

109 plants. To our knowledge, this is the first report of a semi-persistent virus manipulating the

110 behaviour of vector insects. 


\section{Materials and methods}

\section{Vegetable material}

113 Solanum tuberosum Phureja group cv., (the Colombian Creole potato) plants were used for

114 all experiments. Virus-free plants were obtained from in vitro culture to prevent

115 contamination. Mini-tubers were planted in a soil-rice husk substrate (3:1) in 5.5 L pots and

116 plants were grown under greenhouse conditions $\left(22-35^{\circ} \mathrm{C}, 4-6\right.$ lux, 50-70\%RH) inside a

117 mesh cage (mesh size $1.35 \mathrm{~mm}$ ) to avoid infestation by insect vectors that could carry

118 PYVV until the fourth week after sowing (code 105 in potato’s BCCH scale). Plants were

119 then transferred to environmental chambers (Sanyo ${ }^{\circledR}$ MLR 351) set to the required

120 conditions $\left(16{ }^{\circ} \mathrm{C} \pm 1\right.$, 4 lux, and $\left.55 \pm 10 \% \mathrm{RH}\right)$. Plants were watered twice per week until

121 reaching field capacity.

122 Infected plants came from symptomatic plants (intreveinal yellowing of primary and

123 secondary veins on the upper third of the plant) collected in the municipality of Subachoque

124 (Cundinamarca, Colombia) (4.978093, -74.155993). Symptomatic field-collected plants

125 were taken to the laboratory and used as donor plants to infect virus-free three-week-old

126 plants, according to the procedure established by Vargas (2010). Newly infected plants

127 were subjected to the same conditions in the environmental chambers as virus-free plants

$128\left(16^{\circ} \mathrm{C} \pm 1,4\right.$ lux, and $\left.55 \pm 10 \% \mathrm{RH}\right)$. Both infected and virus-free plants were subsequently

129 evaluated for the presence or absence of the virus by RT-PCR according to the protocol

130 established by Hernandez-Guzmán and Guzmán-Barney (2014). Plants were classified as

131 symptomatic, asymptomatic, and virus-free plants for the experiments. 


\section{Whitefly rearing}

133 GWF adults were obtained from the colony at AGROSAVIA’s entomology lab, (Tibaitatá

134 Research Centre, Mosquera, Colombia). GWF was reared on bean plants (Phaseolus

135 vulgaris L.) in order to avoid contact with a possible PYVV host in an isolated room in a

136 glasshouse $\left(22-35^{\circ} \mathrm{C}, 4-6\right.$ lux, 50-70\%RH). Viruliferous insects were obtained by allowing

137 them to feed on symptomatic plants obtained from the field, confirmed through RT-PCT.

138 Transmission of PYVV by action of viruliferous GWF was by releasing 30 newly emerged

139 GWF adults on leaves of plants expressing PYVD symptoms. Whiteflies were kept in

140 clamp cages on the underside of symptomatic potato leaves for 48 hours. Insects were then

141 transferred to virus-free plants using the same method to infect new plants. Insects could

142 feed for 48 hours and were then removed. To confirm the presence of PYVV in the plants,

143 RT-PCR was performed as described below.

144 Life cycle parameter bioassays

145 In order to determine the effect of PYVD symptoms on development and survival rates of

146 GWF individuals, an experiment with three treatments in a completely randomized design

147 was established. Healthy, infected symptomatic and infected asymptomatic plants were

148 placed in environmental chambers at $16{ }^{\circ} \mathrm{C} \pm 1$, 4 lux, and $55 \pm 10 \% \mathrm{RH}$. Ten male-female

149 pairs of GWF adults were released in leaf cages on the underside of three randomly-

150 selected leaflets of each plant. Each treatment consisted of eight plants. After 48 hours,

151 adults were removed from the plants and the number of live and dead nymphs, and

152 development stage (eggs, nymphs, adults) were registered daily for 60 days or until all

153 immature GWF emerges as adults or died. 


\section{Free-choice bioassays}

155 Free-choice bioassays were carried out under controlled conditions $\left(16^{\circ} \mathrm{C} \pm 1,4 \mathrm{Lux}, 65 \%\right.$ -

156 75\% RH) at the Tibaitatá Research Centre. GWF were collected from the colony and kept

157 in a $5 \mathrm{~mL}$ cup. GWF were then transferred to a freezer $\left(4^{\circ} \mathrm{C} \pm 1\right)$ for five minutes to reduce

158 their mobility. Virus-free, symptomatic and asymptomatic leaves were kept in vials with

159 water inside mesh cages ( 1 x 1 x 0.8 m) equidistant in a triangular arrangement, $30 \mathrm{~cm}$

160 apart. Ten GWF adults were then released in the centroid of the triangle, and the number of

161 adults on each leaf was evaluated after 30, 60, 120, 240, and 1440 minutes. Each trial was

162 repeated 30 times using different leaves and insects (300 insects total). Bioassays were

163 preformed using both non-viruliferous and viruliferous insects to determine if there were

164 host preference changes due to virus uptake.

\section{RT-PCR detection}

166 RNA extraction was carried out using the protocol described by Hernandez-Guzmán and

167 Guzmán-Barney (2014). All RNA extracts were obtained using Trizol® (Invitrogen)

168 according to the manufacturer's instructions. The cDNA synthesis was carried out by

169 mixing $2 \mu \mathrm{L}$ of $1 \mathrm{X}$ reaction buffer, $0.5 \mu \mathrm{L}$ of $1 \mathrm{mM}$ dNTPs, $1 \mu \mathrm{L}$ of $10 \mathrm{mM}$ DTT, $0.5 \mu \mathrm{L}$

170 of $0.4 \mu \mathrm{M}$ of 3' reverse primer, $0.4 \mu \mathrm{L}$ of RNase inhibitor, $0.5 \mu \mathrm{L}$ of MMLV HP and 100

171 ng of RNA for each reaction. The mix was kept at $42{ }^{\circ} \mathrm{C}$ for one hour followed by

172 denaturation at $70^{\circ} \mathrm{C}$ for $10 \mathrm{~min}$.

173 The PCR reactions contained $2 \mu \mathrm{L}$ of cDNA, $2 \mu \mathrm{L}$ of $1 \mathrm{X}$ NH4 buffer, $1 \mu \mathrm{L}$ of $25 \mathrm{mM}$

$174 \mathrm{MgCl} 2,0.4 \mu \mathrm{L}$ of $10 \mu \mathrm{M}$ dNTPs, $0.4 \mu \mathrm{L}$ of each forward, and reverse primers to obtain a

175 final volume of $10 \mu \mathrm{L}$. The amplification program was set to an initial denaturation at 94

$176{ }^{\circ} \mathrm{C}$ for $3 \mathrm{~min}, 35$ cycles of denaturation at $94^{\circ} \mathrm{C}$ for $1 \mathrm{~min}$, alignment at $55^{\circ} \mathrm{C}$ for $1 \mathrm{~min}$ and 
177 extension at $72^{\circ} \mathrm{C}$ for $1 \mathrm{~min}$ followed by a final extension at $72^{\circ} \mathrm{C}$ for $10 \mathrm{~min}$. As a positive

178 control, a leaf sample of potato plants expressing PYVD symptoms was included. As

179 negative controls, a leaf sample of a cape gooseberry plant (Physalis peruviana) infected

180 with Tobacco mosaic virus (TMV), and a virus-free potato leaf sample (obtained by in vitro

181 meristems culture).

\section{Data analysis}

183 To compare the average development times of nymphs that fed on symptomatic,

184 asymptomatic and virus-free plants, log-logistic models were constructed describing the 185 proportion of emerged adults, as a function of time, $t$ :

$\frac{1}{1+(b(\log (t)-\log (e)))}$

187 where $b$ and $e$ are parameters estimated from the data, the former denotes the steepness of

188 the curve and the last equals the midpoint of the s-shaped curve. Parameter $e$ (average time 189 at which 50\% of adults emerge) was used to compare development times among treatments

190 (healthy, asymptomatic and symptomatic plants). The parameters were estimated by

191 maximum likelihood estimation, assuming a binomial distribution of the response variable.

192 Comparison of estimates of $e$ were compared through t-tests.

193 To assess differences in survival of individuals feeding on the healthy, symptomatic and

194 asymptomatic plants, a generalized linear model with a binomial distribution was fit. The

195 treatment (virus-free, asymptomatic infected and symptomatic infected) was used as an 196 explanatory variable with virus-free plants as the reference factor level. The magnitude of 197 the difference and the significance between the symptomatic, asymptomatic and virus-free 
198 levels was examined by Tukey’s post-hoc range test analysis adjusted for generalized

199 models (Bretz, Dette, \& Pinheiro, 2010).

200 For the free-choice bioassays, a multinomial regression analysis was fit for both non-

201 viruliferous and viruliferous GWF to model the proportion of adults selecting each

202 treatment over time. The significance of each model was tested against the null model using

203 a chi-square test. To test for differences within each evaluation time (against the null

204 hypothesis of GWF adults selecting treatments at equal proportions), repeated G-test of

205 goodness-of-fit were performed. G-tests are similar to chi-squared test of goodness-of-fit,

206 but they allow for the inclusion of repetitions (trials), because the G-values of independent

207 repetitions add up to an overall G-value for the whole experiment (Agresti, 2018). Thus, G-

208 values for each trial were estimated and then they were summed for each evaluation time.

209 P-values were calculated from chi-squared distributions using the summed degrees of

210 freedom for each evaluation time. We also performed chi-squared pairwise comparisons of

211 proportions as poshoc tests with the data of evaluation times for which significant

212 deviations from equal probabilities were detected with G-tests. Holm's correction was

213 included to adjust P-values for multiple comparisons (Wright, 1992).

214 All analyses were carried out using R software (R Core Team, 2020). The package “drc”

215 was used for parameter estimation of development models (Ritz, Baty, Streibig, \& Gerhard, 216 2016), and G-tests for free-choice data were performed using “DescTools” (Signorell et al., 217 2020). 


\section{Results}

\section{Presence of Potato yellow vein virus (PYVV)}

220 A total of 72 plants were tested. Of the 72 plants, 24 came from in vitro microtubers and all

221 tested negative for PYVV. The remaining 48 plants (24 symptomatic and 24 asymptomatic)

222 came from symptomatic field-collected plants according to the infection protocol above.

223 All 48 plants tested positive for PYVV in RT-PCR analyses. These results confirm that our

224 interpretation of disease symptoms is adequate and that our infection procedure was

225 effective. Of each set of plants, six were used in life parameter assays and the rest were

226 used to obtain leaflets for behavioural experiments.

\section{Life cycle parameters}

228 Symptom expression had a significant effect on the life cycle of GWF. Nymphs fed on

229 infected plants with yellowing symptoms took longer to develop into adults (58.643 \pm

2300.147 days) than those fed on healthy (53.086 \pm 0.1697 days) or asymptomatic plants

231 (50.571 \pm 0.109 days). Interestingly, GWF fed on infected asymptomatic plants developed

232 significantly faster than those fed virus-free plants (Figure 1A). 


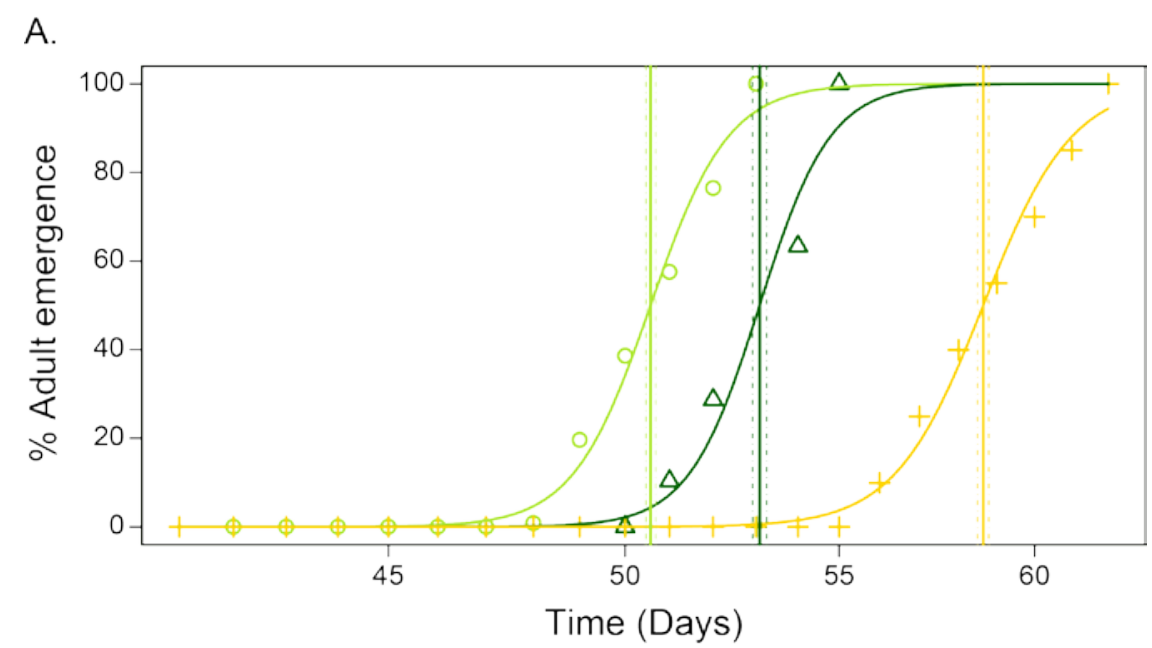

B.

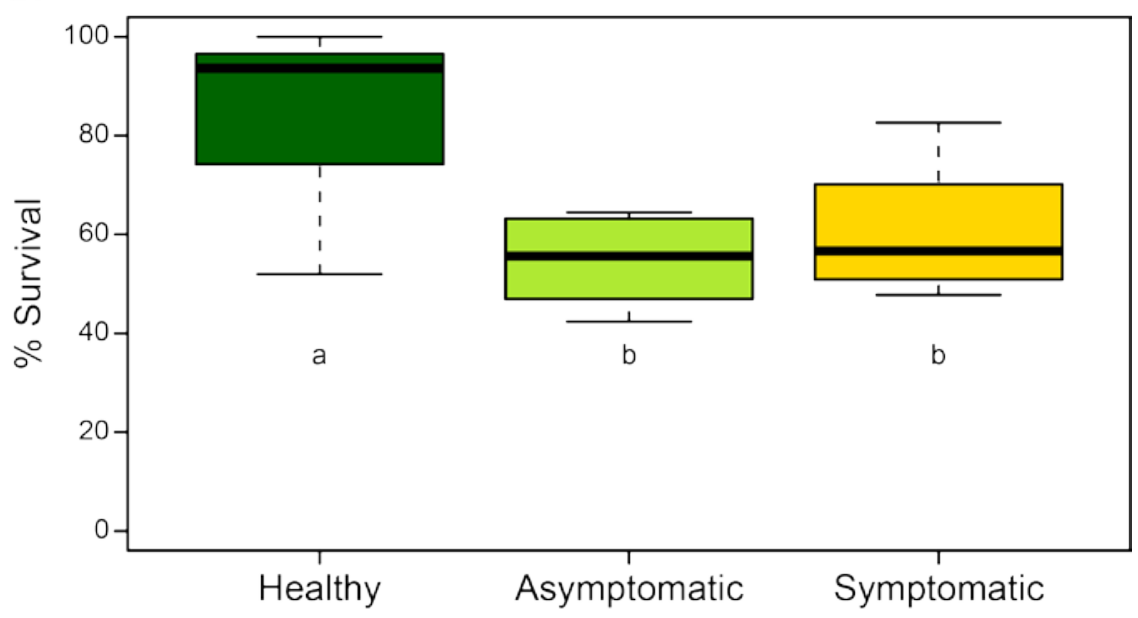

234 Figure 1: Adult emergence and survival. A. Time in days needed by GWF to reach

235 adulthood when reared on healthy potato plants (dark green), PYVV infected,

236 asymptomatic plants (light green) and PYVV infected, symptomatic plants (yellow). Lines

237 represent the average emergence time and the 95\% confidence interval. B. Percent of

238 nymph survival to adulthood when reared on healthy potato plants (dark green), PYVV

239 infected, asymptomatic plants (light green) and PYVV infected, symptomatic plants

240 (yellow).

241 We found that survival rate of GWF nymphs was significantly affected by PYVV infection

$242\left(X^{2}=81.059, P<0.001\right)$. In fact, the poshoc analysis revealed that PYVV infection 
243 affected survival of GWF nymphs regardless symptom expression, since survival was

244 equally reduced in nymphs fed with either symptomatic (mean survival $=60.702 \pm 4.414$

$245 \%$ ) or asymptomatic plants (mean survival = $54.803 \pm 3.079 \%$ ), compared to those that

246 were fed in healthy plants (mean survival = $85.072 \pm 6.186 \%$ ) (Figure 1B).

247 Free-choice bioassays

\section{Non-viruliferous GWF host choice and settlement}

249 Host-plant preference of GWF adults without previous exposure to PYVV was consistent

250 throughout the observation time, according to the multinomial regression model $\left(X^{2}=\right.$

$2512,300, P=0.3166)$. GWF adults consistently preferred symptomatic, followed by

252 asymptomatic and rarely chose, and settled on healthy leaflets (Figure 2A, Table 1).
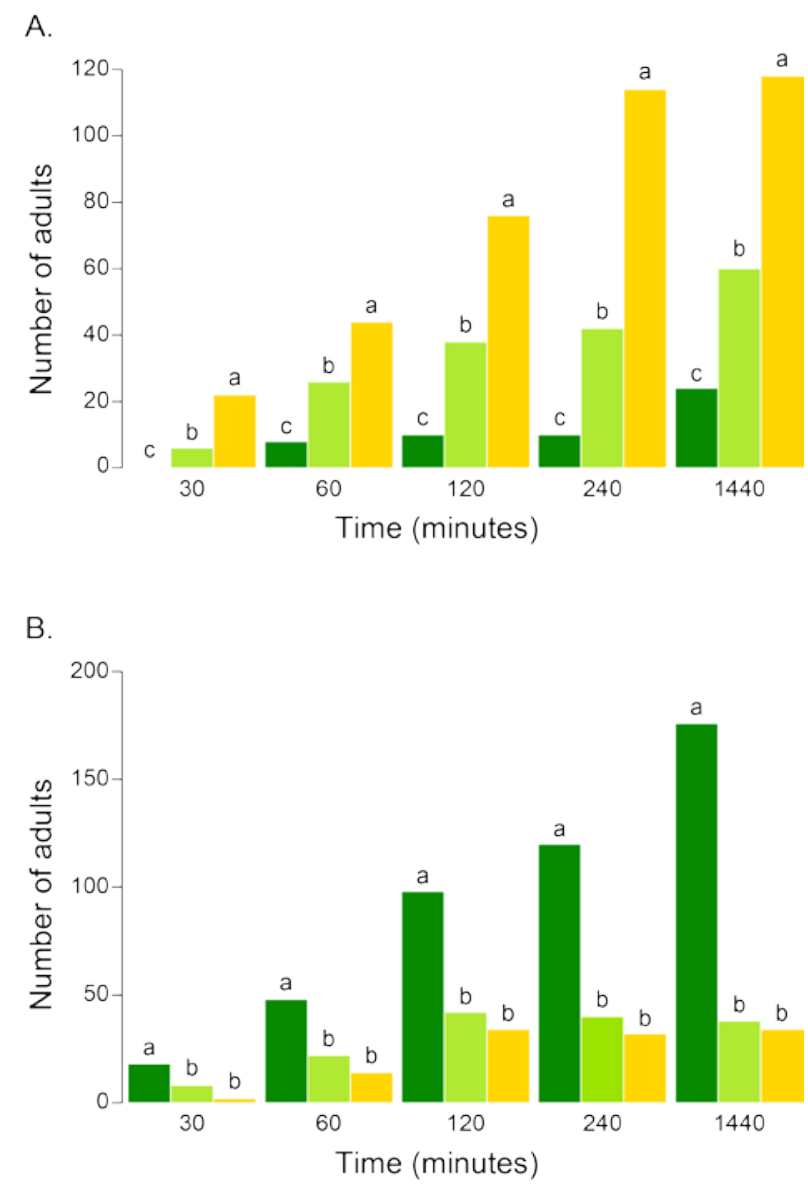
254 Figure 2. Host plant preference of GWF adults over time. A. Host plant choice of non-

255 viruliferous (previously fed on bean plants) GWF adults in three-way experiments. B. Host

256 plant choice of viruliferous (previously fed on PYVD symptomatic potato plants) GWF

257 adults in three-way experiments. Dark green bars represent healthy potato plants, light

258 green bars represent PYVV infected, asymptomatic plants and yellow bars represent PYVV

259 infected, symptomatic plants. Different letters above the bars denote significant differences,

260 according to chi-squared pairwise comparisons $(P<0.05)$, which were performed for each

261 evaluation time independently.

262 Table 1. Repeated G-tests of goodness-of-fit for each evaluation time for a free-choice test

263 with adults of Trialeurodes vaporariorum with no previous contact with PYVV. The G-

264 value presented is the summed value of independent repetitions for each time. Degrees of

265 freedom (DF) differ among times because the trials with no responses were removed from

266 the analysis $(N=30)$.

T1 (30 min) $\quad$ T2 (60 min) $\quad$ T3 (120 min) $\quad$ T4 (240 min) $\quad$ T5 (1440

min)

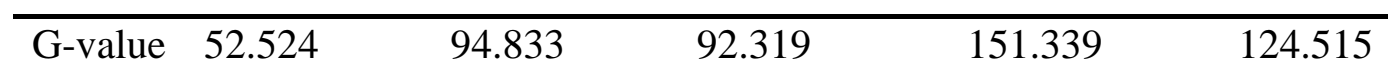

\begin{tabular}{llllll}
\hline DF & 32 & 60 & 60 & 60 & 60
\end{tabular}

\begin{tabular}{llllll}
\hline$P$ & 0.0125 & 0.0027 & 0.0046 & $<0.0001$ & $<0.0001$
\end{tabular}

267 Viruliferous GWF host choice and settlement

268 GWF adults that had previous experience feeding on PYVV-infected plants showed a

269 contrasting host-plant preference in relation with conspecifics without such experience. We

270 found that the proportion of insects that chose healthy leaflets over symptomatic or

271 asymptomatic leaflets increased over time $\left(\mathrm{X}^{2}=8.992, P=0.011\right)$ (Figure 2B). No 
272 differences were detected in preference for PYVV-infected leaflets, whether they were

273 symptomatic or not (Figure 2B, Table 2).

274 Table 2. Repeated G-tests of goodness-of-fit for each evaluation time for a free-choice test

275 with adults of Trialeurodes vaporariorum with previous contact with PYVV. The G-value

276 presented is the summed value of independent repetitions for each time. Degrees of

277 freedom (DF) differ among times because the trials with no responses were removed from

278 the analysis $(N=30)$.

\section{T1 (30 min) $\quad$ T2 (60 min) $\quad$ T3 (120 min) $\quad$ T4 (240 min) $\quad$ T5 (1440}

\begin{tabular}{lllllc} 
& & & & min) \\
\hline G-value & 50.431 & 92.070 & 99.6371 & 146.736 & 215.992 \\
\hline DF & 28 & 56 & 60 & 60 & 60 \\
\hline$P$ & 0.0057 & 0.0017 & 0.00099 & $<0.0001$ & $<0.0001$ \\
\hline
\end{tabular}

\section{Discussion}

280 It is difficult to understand how a generalist insect, such as the GWF, could begin to

281 actively prefer a non-host plant. In order for this to happen, either the insect would need to

282 change its preferences to include the previously non-host plant, or the plant would need to

283 begin giving off the proper cues for the insect to begin finding it attractive. While this kind

284 of cognitive change is less likely to occur and establish itself in an insect population

285 (Libersat, Kaiser, \& Emanuel, 2018), it is common for plant’s metabolism to be altered by

286 biotic (diseases, herbivory, phenology) and abiotic (drought, nutrient stress) factors in such

287 a way that the cues they produce change substantially. Such cues (often associated with

288 symptom expression) may include changes in plant coloration and leaf structure (Lu et al., 
2017), volatile profile (Fereres et al., 2016), nutritional quality (Bosque-Pérez \&

290 Eigenbrode, 2011; Kerry E. Mauck et al., 2018; Szczepaniec \& Finke, 2019), and/or

291 nutrient allocation (Byrne \& Bellows Jr, 1991; Fereres, 2015; Szczepaniec \& Finke, 2019).

292 Physical and chemical cues generated by virus-infected hosts are fundamental to the

293 behavioural manipulation of insect vectors. Behavioural manipulation of insect vectors

294 through symptom expression has been widely studied in different plant-virus families

295 (Colvin et al., 2006; Fereres et al., 2016; Van Roermund \& van Lenteren, 1992) including

296 criniviruses (Jones, 2003; Martelli et al., 2002; Navas-Castillo, López-Moya, \& Aranda,

297 2014; Osorio et al., 2016). Yellowing, the most noticeable symptom of PYVD, plays an

298 important role in turning potato plants from being unattractive for GWF into a potential

299 host. Like many hemipterans, GWF is attracted to yellow (Vaishampayan, Kogan,

300 Waldbauer, \& Woolley, 1975) so it could be predicted that yellowing would increase

301 attraction of GWF to a non-plant. Our results show that this is, in fact, the case. Non-

302 viruliferous GFW adults significantly prefer leaves that express PPYD yellowing over

303 green leaves and remain and feed on them in approximately constant proportions, at least

304 over the duration of our experiment (1440 minutes). By doing so, they accomplish the first

305 step required for there to be horizontal transmission of PYVV which is the uptake of the

306 virus. Curiously, leaves from infected, asymptomatic plants show an intermediate attraction

307 and arrestment of GWF adults, suggesting that while not obvious to us, there are more

308 symptoms at play that we are unable to easily detect, such as changes in the volatile profile

309 of plants. It remains to be seen if these unseen symptoms of infected plants that have not

310 begun to express yellowing are enough to attract GWF in the field. 
311 The second key factor for horizontal transmission through vectors to be feasible is

312 arrestment of insects on infected plants in order for them to uptake the virus. According to

313 the postulates of semi-persistent virus transmission, vectors should spend a moderate

314 amount of time feeding on infected plants in order to acquire enough viral titre to establish

315 itself in the insect's mouth parts and foregut before they move to a new host. The fact that

316 GWF development rate is slower when individuals are reared on symptomatic plants

317 compared to when they develop in healthy plants is likely an effect of reduced nutritional

318 properties of diseased plants, but it may also favour the uptake of viral particles through

319 prolonged feeding duration, likely facilitating horizontal transmission. In fact, such

320 decreased nutritional quality of infected plants may explain why nymphs fed with both

321 symptomatic and asymptomatic plants showed reduced survival compared to those fed with

322 healthy plants (Chesnais et al., 2019). The reduced nutritional quality of infected plants

323 may also be a stimulus for adult GWF to seek out a better-quality host, leading to the third

324 necessary step for horizontal transmission to occur. Curiously, GWF development rate

325 increased when nymphs were reared on infected, asymptomatic plants, suggesting that there

326 may be benefits to feeding on plants that do not express symptoms compared to both

327 healthy and symptomatic plants. Plants being attacked by a virus and an insect,

328 simultaneously, must spend more energy on defences for both. However, if insects arrive

329 on a plant which has already been infected, but whose nutritional quality is not affected yet,

330 it may be able to take advantage of the fact that the plant is already using resources and

331 activating its defences against the virus, and increase its ability to reproduce and develop.

332 Virus-free plants, on the other hand, may concentrate their defences against the insect

333 herbivore, thus reducing their reproductive potential and increasing their development time 
334 (Bak, Cheung, Yang, Whitham, \& Casteel, 2017; Gallet et al., 2018; Tzanetakis, Martin, \&

335 Wintermantel, 2013).

336 Combined with reduced nutritional quality, we see that viral acquisition also seems to

337 directly affect GWF host preference. Interestingly, although only the proximal parts of the

338 midgut and mouthparts are reached by semi-persistent viruses, PYVV seems to be able to

339 alter vector host preference to increase the dispersion of viral particles from infected to

340 healthy hosts. Similar to what has been observed in other systems such as that of Tomato

341 severe rugose virus (ToSRV, Geminiviridae) and Tomato chlorosis virus (ToCV,

342 Closteroviridae) (Bosque-Pérez \& Eigenbrode, 2011; Casteel et al., 2014; Fereres et al.,

343 2016; Peñaflor, Mauck, Alves, De Moraes, \& Mescher, 2016; Wu, Davis, \& Eigenbrode,

344 2014), GWF adults change their host preference as a function of their previous exposure to

345 PYVV-infected plants. Changes in insect host-preference modulated by the pre-acquisition

346 of viruses has been well documented for persistent viruses which replicate inside the vector

347 (He, Li, \& Liu, 2015). However, our results show that a semi-persistent virus, through an

348 unknown mechanism, may also modulate insect behaviour in contrast to what has been

349 previously reported in other studies (Whitfield, Falk, \& Rotenberg, 2015). This highlights

350 the lack of understanding we have on semi-persistent viruses and how broad the spectrum

351 of characteristics between non-persistent and persistent viruses actually is. It is likely that,

352 while PYVV may not directly affect GWF cognitive behaviour, classical conditioning of

353 GWF adults may explain GWF behavioural manipulation through symptom expression

354 after PYVV infection in potato plants. We hypothesize that the exposure of GWF adults to

355 low-quality hostplants (e.g., infected, symptomatic potato plants) may alter GWF's further

356 associations of stimuli with preferred hosts. If that is the case, the whole profile of cues 
357 associated with PYVV-infected, symptomatic plants will no longer be used to recognize

358 suitable hosts by experienced GWF adults. Effects of previous experience on host-selection

359 by whiteflies, including the GWF, has been documented elsewhere (Lee, Nyrop, \&

360 Sanderson, 2010; Shah \& Liu, 2013), and classical conditioning has also been reported for

361 other Hemiptera (Stockton, Martini, Patt, \& Stelinski, 2016).

362 In the PYVV-GWF-potato system, symptom expression reduces tuber formation (and

363 vertical transmission rates) (Guzmán-Barney et al., 2012), so it is expected that symptoms

364 are part of an effective strategy to maximize vector-borne (horizontal) transmission. The

365 changes caused by PYVD on host plants are consistent with the hypothesis that the

366 generation of symptoms by viral infection modifies insect vector behaviour and

367 development to enhance horizontal transmission. Our results suggest that semi-persistent

368 viruses have far more complex strategies for horizontal transmission than was previously

369 thought. Even though we have shown that a semi-persistent virus may affect vector

370 attraction, arrestment, and new host plant choice through the expression of symptoms, the

371 mechanisms behind this behavioural modulation remain unclear. Further experiments into

372 symptoms, such as changes in volatile profiles, and their comparisons to those of GWF

373 hosts are crucial to understand the ecology behind the host plant shift observed.

374 Bromatological studies will help us to understand how the virus could manipulate both

375 vector arrestment and release in order to make sure that there is sufficient uptake of viral

376 particles. Lastly, it would be interesting to see what the effects of viral uptake are on GWF

377 physiology and brain chemistry. It remains difficult to understand how a virus which does

378 not persist for long periods of time in an insect, or replicate within, is capable of completely

379 reversing host-choice. Understanding the underlaying mechanism behind this will broaden 
380 our understanding of semi-persistent and perhaps break the boundaries of viral

381 classification.

\section{Conclusions}

383 We evidenced that physiological changes derived from PYVV infection in potato plants

384 alter development, survival and behaviour of the insect vector, the GWF. In particular, the

385 characteristic yellowing seems to be associated with low-nutritional quality (longer

386 immature development times and reduced survival) for the GWF, but quite attractive to

387 GWF adults with no previous exposure to PYVV-infected plants. In contrast, green, healthy

388 plants seem to provide better nutritional quality (shorter immature development times) than

389 infected plants for the GWF and be particularly attractive to adults that had been previously

390 exposed to PYVV-infected plants. Altogether, we present new insights on the ecological

391 relationships between viruses, plants and insect vectors, and how physiological and

392 morphological consequences of viral infections in plants may act as modulators of plant-

393 vector interactions.

\section{Acknowledgements}

395 We are grateful to Anngie K. Hernandez and Diana M. Torres (AGROSAVIA) who carried

396 PYVV detection tests on potato seed tubers. This study was funded by the Ministerio de

397 Agricultura y Desarrollo Rural de Colombia with government funds allocated to the

398 Corporación Colombiana de Investigación Agropecuaria (AGROSAVIA) (Grant:

399 “Generación y validación de tecnologías sostenibles de producción para incrementar la

400 competitividad de la cadena de la papa en Colombia”). Research support was provided by 
401 government funds assigned to AGROSAVIA. The authors assume full responsibility for the

402 interpretation of results and ideas presented in this manuscript.

\section{Conflict of Interests}

404 The authors declare that there are no conflicts of interest

\section{Author contribution}

406 All authors contributed equally to the analysis of results, writing and reviewing of the

407 manuscript.

408 DFV: Contributed to the original idea as well as the hypotheses. Designed, and carried out

409 the experiments. Collected and organized data. Contributed to the statistical analysis.

410 DFR: Had the original idea and contributed to the consolidation of the hypotheses. Helped

411 in the organization and systematization of the data. Carried out statistical analysis.

412 FB-E: Contributed to the consolidation of the hypotheses. Contributed to the design of

413 experiments.

\section{Data Availability}

415 The datasets generated, collected and/or analyzed during the current study are available

416 from the corresponding author on reasonable request, according to institutional guidelines.

\section{References}

418 Agresti, A. (2018). An introduction to categorical data analysis: John Wiley \& Sons.

419 Alizon, S., Hurford, A., Mideo, N., \& Van Baalen, M. (2009). Virulence evolution and the 420 trade-off hypothesis: history, current state of affairs and the future. J Evol Biol, 22(2), 245-259. doi: 10.1111/j.1420-9101.2008.01658.x

Bak, A., Cheung, A. L., Yang, C., Whitham, S. A., \& Casteel, C. L. (2017). A viral protease relocalizes in the presence of the vector to promote vector performance. Nature Communications, 8(1), 14493. doi: 10.1038/ncomms14493 
425

Bosque-Pérez, N. A., \& Eigenbrode, S. D. (2011). The influence of virus-induced changes in plants on aphid vectors: Insights from luteovirus pathosystems. Virus Research, 159(2), 201-205. doi: 10.1016/j.virusres.2011.04.020

Bretz, F., Dette, H., \& Pinheiro, J. C. (2010). Practical considerations for optimal designs in clinical dose finding studies. Statistics in Medicine, 29(7-8), 731-742. doi: 10.1002/sim.3802

Byrne, D. N., \& Bellows Jr, T. S. (1991). Whitefly biology. Annual Review of Entomology, 36(1), 431-457.

Casteel, C. L., \& Jander, G. (2013). New synthesis: Investigating mutualisms in virus-vector interactions. Journal of Chemical Ecology, 39(7), 809-809. doi: 10.1007/s10886-0130305-0

Casteel, C. L., Yang, C., Nanduri, A. C., De Jong, H. N., Whitham, S. A., \& Jander, G. (2014). The NIa-Pro protein of Turnip mosaic virus improves growth and reproduction of the aphid vector, Myzus persicae (green peach aphid). The Plant Journal, 77(4), 653-663. doi: 10.1111/tpj.12417

Chesnais, Q., Mauck, K. E., Bogaert, F., Bamière, A., Catterou, M., Spicher, F., . . Ameline, A. (2019). Virus effects on plant quality and vector behavior are species specific and do not depend on host physiological phenotype. Journal of Pest Science, 92(2), 791804. doi: 10.1007/s10340-019-01082-z

Colvin, J., Omongo, C. A., Govindappa, M. R., Stevenson, P. C., Maruthi, M. N., Gibson, G., ... Muniyappa, V. (2006). Host-plant viral infection effects on arthropod-vector population growth, development and behaviour: Management and epidemiological implications Advances in Virus Research (Vol. 67, pp. 419-452): Academic Press.

Cuadros, D. F., Hernandez, A., Torres, M. F., Torres, D. M., Branscum, A. J., \& Rincon, D. F. (2017). Vector transmission alone fails to explain the potato yellow vein virus epidemic among potato crops in Colombia. [Original Research]. Frontiers in Plant Science, 8(1654), 1654. doi: 10.3389/fpls.2017.01654

Curry, J. P., \& Pimentel, D. (1971). Life cycle of the Greenhouse Whitefly, Trialeurodes vaporariorum, and population trends of the whitefly and its parasite, Encarsis formosa, on two tomato varieties. Annals of the Entomological Society of America, 64(5), 1188-1190. doi: 10.1093/aesa/64.5.1188 \%J

Fereres, A. (2015). Insect vectors as drivers of plant virus emergence. Current Opinion in Virology, 10(Complete), 42-46. doi: 10.1016/j.coviro.2014.12.008

Fereres, A., \& Moreno, A. (2009). Behavioural aspects influencing plant virus transmission by homopteran insects. Virus Research, 141(2), 158-168. doi: 10.1016/j.virusres.2008.10.020

Fereres, A., Peñaflor, M. F. G., Favaro, C. F., Azevedo, K. E., Landi, C. H., Maluta, N. K., . . . Lopes, J. R. J. V. (2016). Tomato infection by whitefly-transmitted circulative and non-circulative viruses induce contrasting changes in plant volatiles and vector behaviour. Viruses, 8(8), 225. doi: 10.3390/v8080225

Gallet, R., Michalakis, Y., \& Blanc, S. (2018). Vector-transmission of plant viruses and constraints imposed by virus-vector interactions. Current Opinion in Virology, 33, 144-150. doi: 10.1016/j.coviro.2018.08.005

Guzmán-Barney, M., Franco-Lara, L., Rodríguez, D., Vargas, L., \& Fierro, J. E. (2012). Yield losses in Solanum tuberosum Group Phureja Cultivar Criolla Colombia in Plants with Symptoms of PYVV in Field Trials. American Journal of Potato Research, 89(6), 438-447. doi: 10.1007/s12230-012-9265-0 
472

473

474

475

476

477

478

479

480

481

482

483

484

485

486

487

488

489

490

491

492

493

494

495

496

497

498

499

500

501

502

503

504

505

506

507

508

509

510

511

512

513

514

515

516

Hamelin, F. M., Allen, L. J. S., Prendeville, H. R., Hajimorad, M. R., \& Jeger, M. J. (2016). The evolution of plant virus transmission pathways. Journal of Theoretical Biology, 396, 75-89. doi: 10.1016/j.jtbi.2016.02.017

He, W.-B., Li, J., \& Liu, S.-S. (2015). Differential profiles of direct and indirect modification of vector feeding behaviour by a plant virus. Scientific Reports, 5(1), 7682. doi: 10.1038/srep07682

Hernández-Guzmán, A. K., \& Guzmán-Barney, M. (2014). Detección del virus del amarillamiento de las nervaduras de la hoja de la papa en diferentes órganos de Solanum tuberosum grupo Phureja cv Criolla Colombia utilizando RT-PCR convencional y en tiempo real. Revista Colombiana de Biotecnología, 16(1), 74-85.

Hogenhout, S. A., Ammar, E.-D., Whitfield, A. E., \& Redinbaugh, M. G. (2008). Insect vector interactions with persistently transmitted viruses. Annual Review of Phytopathology, 46(1), 327-359. doi: 10.1146/annurev.phyto.022508.092135

Jia, D., Chen, Q., Mao, Q., Zhang, X., Wu, W., Chen, H., . . Wei, T. (2018). Vector mediated transmission of persistently transmitted plant viruses. Current Opinion in Virology, 28, 127-132. doi: 10.1016/j.coviro.2017.12.004

Jones, D. R. (2003). Plant viruses transmitted by whiteflies. European Journal of Plant Pathology, 109(3), 195-219. doi: 10.1023/A:1022846630513

Lee, D.-H., Nyrop, J. P., \& Sanderson, J. P. (2010). Effect of host experience of the greenhouse whitefly, Trialeurodes vaporariorum, on trap cropping effectiveness. Entomologia Experimentalis et Applicata, 137(2), 193-203. doi: 10.1111/j.15707458.2010.01052.x

Libersat, F., Kaiser, M., \& Emanuel, S. (2018). Mind control: How parasites manipulate cognitive functions in their insect hosts. [Perspective]. Frontiers in Psychology, 9(572). doi: 10.3389/fpsyg.2018.00572

Lipsitch, M., Siller, S., \& Nowak, M. A. (1996). The evolution of virulence in pathogens with vertical and horizontal transmission. Evolution, 50(5), 1729-1741. doi: 10.1111/j.1558-5646.1996.tb03560.x

Lu, S., Li, J., Wang, X., Song, D., Bai, R., Shi, Y., . . Yan, F. (2017). A semipersistent plant virus differentially manipulates feeding behaviors of different sexes and biotypes of its whitefly vector. Viruses, 9(1), 4. doi: 10.3390/v9010004

Martelli, G. P., Agranovsky, A. A., Bar-Joseph, M., Boscia, D., Candresse, T., Coutts, R. H. A., . . . Yoshikawa, N. (2002). The family Closteroviridae revised. Archives of Virology, 147(10), 2039-2044. doi: 10.1007/s007050200048

Mauck, K. E., Chesnais, Q., \& Shapiro, L. R. (2018). Evolutionary determinants of host and vector manipulation by plant viruses. In C. M. Malmstrom (Ed.), Advances in Virus Research (Vol. 101, pp. 189-250): Academic Press.

Mauck, K. E., De Moraes, C. M., \& Mescher, M. C. (2016). Effects of pathogens on sensorymediated interactions between plants and insect vectors. Current Opinion in Plant Biology, 32, 53-61.

Messenger, S. L., Molineux, I. J., \& Bull, J. J. (1999). Virulence evolution in a virus obeys a trade-off. Proc Biol Sci, 266(1417), 397-404. doi: 10.1098/rspb.1999.0651

Navas-Castillo, J., López-Moya, J. J., \& Aranda, M. A. (2014). Whitefly-transmitted RNA viruses that affect intensive vegetable production. Annals of Applied Biology, 165(2), 155-171. doi: 10.1111/aab.12147 
Ng, J. C. K., \& Zhou, J. S. (2015). Insect vector-plant virus interactions associated with noncirculative, semi-persistent transmission: Current perspectives and future challenges. Current Opinion in Virology, 15, 48-55. doi: 10.1016/j.coviro.2015.07.006

Osorio, M., Marques, A., Romay, G., Roa, S., Demey, J., \& Vegas, A. (2016). Adaptación de la técnica RT-PCR para el diagnóstico del virus del amarillamiento de las venas de papa en Venezuela. Bioagro, 28(1), 047-052.

Pagán, I., Montes, N., Milgroom, M. G., \& García-Arenal, F. (2014). Vertical transmission selects for reduced virulence in a plant virus and for increased resistance in the host. PLOS Pathogens, 10(7), e1004293. doi: 10.1371/journal.ppat.1004293

Peñaflor, M. F. G. V., Mauck, K. E., Alves, K. J., De Moraes, C. M., \& Mescher, M. C. (2016). Effects of single and mixed infections of Bean pod mottle virus and Soybean mosaic virus on host-plant chemistry and host-vector interactions. Functional Ecology, 30(10), 1648-1659. doi: 10.1111/1365-2435.12649

R Core Team. (2020). R: A Language and environment for statistical computing (Version Version 3.5.1. "Feather Spray"). Vienna, Austria: R Foundation for Statistical Computing. Retrieved from http://www.R-project.org/

Rincon, D. F., Vasquez, D. F., Rivera-Trujillo, H. F., Beltrán, C., \& Borrero-Echeverry, F. (2019). Economic injury levels for the potato yellow vein disease and its vector, Trialeurodes vaporariorum (Hemiptera: Aleyrodidae), affecting potato crops in the Andes. Crop Protection, 119, 52-58. doi: 10.1016/j.cropro.2019.01.002

Ritz, C., Baty, F., Streibig, J. C., \& Gerhard, D. (2016). Dose-response analysis using R. PLOS ONE, 10(12), e0146021. doi: 10.1371/journal.pone.0146021

Shah, M. M. R., \& Liu, T.-X. (2013). Feeding experience of Bemisia tabaci (Hemiptera: Aleyrodidae) affects their performance on different host plants. PloS one, 8(10), e77368-e77368. doi: 10.1371/journal.pone.0077368

Signorell, A., Aho, K., Alfons, A., Anderegg, N., Aragon, T., Arppe, A., . . . Zeileis, A. (2020). DescTools: tools for descriptive statistics. R package version 0.99. 34 .

Stockton, D. G., Martini, X., Patt, J. M., \& Stelinski, L. L. (2016). TheiInfluence of learning on host plant preference in a significant phytopathogen vector, Diaphorina citri. PLOS ONE, 11(3), e0149815. doi: 10.1371/journal.pone.0149815

Su, Q., Preisser, E. L., Zhou, X. M., Xie, W., Liu, B. M., Wang, S. L., .. . Zhang, Y. J. (2015). Manipulation of host quality and defense by a plant virus improves performance of whitefly vectors. Journal of Economic Entomology, 108(1), 11-19. doi: 10.1093/jee/tou012 \% J

Szczepaniec, A., \& Finke, D. (2019). Plant-vector-pathogen interactions in the context of drought stress. [Mini Review]. Frontiers in Ecology and Evolution, 7(262). doi: 10.3389/fevo.2019.00262

Tzanetakis, I., Martin, R., \& Wintermantel, W. (2013). Epidemiology of criniviruses: An emerging problem in world agriculture. [Review]. frontiers in Microbiology, 4(119), 119. doi: $10.3389 /$ fmicb.2013.00119

Vaishampayan, S. M., Kogan, M., Waldbauer, G. P., \& Woolley, J. T. (1975). Spectral specific responses in the visual behavior of the Greenhouse Whitefly, Trialeurodes Vaporariorum (Homoptera: Aleyrodidae). Entomologia Experimentalis et Applicata, 18(3), 344-356. doi: 10.1111/j.1570-7458.1975.tb00407.x

Van Roermund, H. J. W., \& van Lenteren, J. C. (1992). The parasite-host relationship between Encarsia formosa (Hymenoptera: Aphelinidae) and Trialeurodes vaporariorum (Homoptera: Aleyrodidae) XXXIV. Life-history parameters of the 

temperature (Vol. 92-3). Wageningen, Netherlands: Wageningen Agricultural University Papers.

Vargas, A. (2010). Respuesta de la Colección Central Colombiana de Solanum tuberosum de la Universidad Nacional de Colombia a la infección con Potato yellow vein virus (PYVV). M.Sc, Universidad Nacional de Colombia, Bogotá, Colombia.

Whitfield, A. E., Falk, B. W., \& Rotenberg, D. (2015). Insect vector-mediated transmission of plant viruses. Virology, 479-480, 278-289. doi: 10.1016/j.virol.2015.03.026

573 1013. doi: $10.2307 / 2532694$

Wu, Y., Davis, T. S., \& Eigenbrode, S. D. (2014). Aphid behavioral responses to virusinfected plants are similar despite divergent fitness effects. Entomologia Experimentalis et Applicata, 153(3), 246-255. doi: 10.1111/eea.12246 